\title{
Severe clinical onset of diabetes and increased prevalence of other autoimmune diseases in children with coeliac disease diagnosed before diabetes mellitus
}

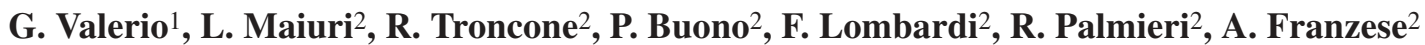 \\ ${ }^{1}$ Faculty of Motoric Sciences, University Parthenope, Naples, Italy \\ 2 Department of Paediatrics, University Federico II, Naples, Italy
}

\section{Abstract}

Aims/hypothesis. To analyse whether the time of diagnosis of coeliac disease with respect to the clinical onset of diabetes could differentiate subgroups of varying severity in patients with both diseases.

Methods. We investigated 383 patients with Type I (insulin-dependent) diabetes mellitus for coeliac disease. Sex distribution, age at diagnosis of diabetes, prevalence of ketoacidosis at the onset of diabetes and prevalence of other autoimmune diseases were compared in patients. We divided these patients according to whether coeliac disease was diagnosed before (Group A, $n=8$ ) or after (Group B, $n=24$ ) diabetes onset and whether they had presented clinical symptoms of coeliac disease. Group C $(n=351)$ included diabetic patients without coeliac disease.

Results. Out of 383 Type I diabetic patients we found 32 coeliac subjects $(8.3 \%)$. There was a higher number of girls $(p=0.003)$, but similar age and prevalence of ketoacidosis compared with Group C; $18.7 \%$ had a third autoimmune disorder. The higher number of girls was confirmed in Groups A and B in comparison to Group C ( $p=0.013)$, while higher prevalence of both ketoacidosis $(p=0.009)$ and other autoimmune diseases $(p=0.001)$ was found only in Group A. Compared with symptomatic patients, asymptomatic subjects in Group $B$ had a lower number of girls, older age at diabetes onset, lower prevalence of ketoacidosis and no other associated autoimmune disease.

Conclusions/interpretation. A wide clinical spectrum characterises the association of coeliac disease and diabetes mellitus, with a severe clinical presentation (higher prevalence of ketoacidosis at the onset and occurrence of other autoimmune diseases) when coeliac disease is diagnosed before diabetes. Distinct phenotypes might imply the contribution of a peculiar genetic background. [Diabetologia (2002) 45:1719-1722]

Keywords Antibody screening, autoimmune diseases, coeliac disease, diabetic ketoacidosis, gluten-free diet, Type I diabetes.
While screening studies show that the worldwide prevalence of coeliac disease (CD) in the general paediatric population is around 1:250 [1], the prevalence of CD in subjects with Type I (insulin-dependent) dia-

Received: 4 March 2002 / Revised: 7 May 2002

Published online: 19 October 2002

C) Springer-Verlag 2002

Corresponding author: A. Franzese, MD, Department of Paediatrics, via S. Pansini 5, 80131 Naples, Italy. E-mail: franzese@unina.it

Abbreviations: AGA, Anti-gliadin antibodies; CD, coeliac disease; DKA, diabetic ketoacidosis; EmA, antiendomisial antibodies; GFD, gluten free diet; T1DM, Type I diabetes mellitus. betes mellitus (T1DM) ranges from 1.1 to $7.8 \%$, depending on different screening methods and whether adult or paediatric patients were examined [2, 3, 4]. The pathogenetic mechanism underlying the simultaneous occurrence of these clustered autoimmune diseases has not been clearly elucidated, even though there is evidence that a common genetic determinant could be involved. So far, the increased prevalence of coeliac disease in patients with Type I diabetes has been in part explained by shared HLA risk alleles, in particular increased frequencies of HLA-DR3 and HLA-DQ2 (which is in linkage disequilibrium with HLA-DR3) [5]. As coeliac disease symptoms are often atypical or absent in Type I diabetic patients, as it 
Table 1. Comparative data of Type I diabetic patients with coeliac disease $\left(\mathrm{CD}^{+} \mathrm{T}^{\mathrm{DDM}}{ }^{+}\right)$and without coeliac disease $\left(\mathrm{CD}-\mathrm{T} 1 \mathrm{DM} \mathrm{M}^{+}\right)$

\begin{tabular}{|c|c|c|c|c|c|c|}
\hline$n$ & $\begin{array}{l}n(\%) \\
\text { Females }\end{array}$ & $\begin{array}{l}\text { Age } \\
\text { (years) }\end{array}$ & $\begin{array}{l}\text { Age at T1DM } \\
\text { diagnosis } \\
\text { (years) }\end{array}$ & $\begin{array}{l}\text { Age at CD } \\
\text { diagnosis } \\
\text { (years) }\end{array}$ & $\begin{array}{l}\text { T1DM } \\
\text { duration } \\
\text { (years) }\end{array}$ & $\%$ GFD \\
\hline
\end{tabular}

\section{$\mathrm{CD}^{+} \mathrm{T}^{\mathrm{DDM}} \mathrm{M}^{+}$}

\begin{tabular}{lrrrlrrr}
$\mathrm{A}$ & 8 & $6(75.0)^{\mathrm{a}}$ & $14.0 \pm 4.7$ & $7.1 \pm 2.9$ & $3.2 \pm 1.5^{\mathrm{c}}$ & $6.9 \pm 3.8$ & 100 \\
$\mathrm{~B}$ & 24 & $17(70.8)$ & $13.8 \pm 5.4$ & $6.7 \pm 3.7$ & $8.8 \pm 4.5$ & $7.8 \pm 4.3$ & 66 \\
$\mathrm{~B}_{1}$ & 15 & $12(80.0)$ & $12.9 \pm 6.2$ & $5.3 \pm 3.6^{\mathrm{b}}$ & $7.3 \pm 4.4^{\mathrm{d}}$ & $8.8 \pm 4.5$ & 54 \\
$\mathrm{~B}_{2}$ & 9 & $5(55.5)$ & $15.3 \pm 3.6$ & $9.1 \pm 2.7$ & $11.4 \pm 3.4$ & $6.7 \pm 4.1$ & 33 \\
\multicolumn{2}{l}{$\mathrm{CD}^{-} \mathrm{T}_{1 D M}{ }^{+}$} & & & & & & \\
$\mathrm{C}$ & 351 & $157(44.7)$ & $13.4 \pm 3.8$ & $7.6 \pm 3.8$ & - & $6.8 \pm 3.8$ & - \\
\hline
\end{tabular}

${ }^{\mathrm{a}} \chi^{2} 8.7, p=0.013$ (Group A and B vs C)

b Student's $t$ test, $p=0.012\left(\mathrm{~B}_{1}\right.$ vs $\left.\mathrm{B}_{2}\right)$

c Student's $t$ test, $p=0.002$ (A vs B)

d Student's $t$ test, $p=0.026\left(\mathrm{~B}_{1}\right.$ vs $\left.\mathrm{B}_{2}\right)$

occurs in the general population, the diagnosis of coeliac disease is often carried out through screening programs. The aim of this investigation was to assess the severity of diabetes onset and the prevalence of other autoimmune disorders in our cohort of $\mathrm{CD}^{+} \mathrm{T} 1 \mathrm{DM}^{+}$ patients, according to the time of clinical diagnosis of $\mathrm{CD}$ with respect to the clinical onset of diabetes.

\section{Subjects and methods}

We studied 383 Type I diabetic patients (194 boys, 189 girls) with a duration of disease of 7.6 \pm 4.2 years (range $2-15$ years). This group represents the whole diabetic population of less than 18 years old attending the Diabetes Unit at the Department of Paediatrics, University Federico II. The period of the study was from January 1992 to December 2000. In 1992, a yearly screening program for coeliac disease among patients with Type I diabetes was started by measuring serum total IgA values and subsequently serum IgA endomysial antibodies (EmA) on a single random blood sample; EmA were detected by means of indirect immunofluorescence assay. Serum from subjects with total IgA $(<5 \mathrm{~g} / \mathrm{l})$ deficiency was alternatively analysed for $\mathrm{IgG}$ anti-gliadin antibodies (AGA), measured by enzyme-linked immunosorbent assay method. Patients positive after screening underwent a diagnostic small bowel biopsy procedure and morphometric/ immunohistochemical studies were carried out to confirm CD diagnosis, which was done according to the revised European Society for Pediatric Gastroenterology and Nutrition criteria [6]. The HLA phenotype was assessed in $\mathrm{CD}^{+} \mathrm{T} 1 \mathrm{DM}^{+}$patients according to standard procedures [7]. All patients diagnosed with coeliac disease were advised to start a gluten free diet (GFD) under the supervision of a trained paediatric dietician and were tested yearly by EmA and/or AGA measurements.

Out of 383 Type I diabetic patients, 32 patients with coeliac disease were found; two of them showed a $\operatorname{IgA}$ deficiency. $\mathrm{CD}^{+} \mathrm{T} 1 \mathrm{DM}^{+}$patients were divided into two groups, based on whether coeliac disease was diagnosed before or after the clinical onset of diabetes. Group A comprised of eight patients who had received coeliac disease diagnosis before diabetes (malabsorption was the main symptom), Group B comprised of 24 patients who had been diagnosed with coeliac disease after the onset of diabetes, as a result of the screening program: 15 had shown typical and/or atypical coeliac disease symptoms [1] $\left(\right.$ Group $\mathrm{B}_{1}$ ), while nine of them were asymptomatic (Group $\mathrm{B}_{2}$ ). Group C included $351 \mathrm{CD}^{-} \mathrm{T}_{1 \mathrm{DM}}{ }^{+}$patients (controls).
The following information was retrieved from the patients' medical records: age at diagnosis of coeliac disease, age at diagnosis of diabetes, clinical manifestations of coeliac disease, occurrence of diabetic ketoacidosis (DKA) at the clinical onset of diabetes, occurrence of additional autoimmune diseases at the onset of diabetes, and family history of autoimmune diseases in the first degree relatives. DKA was defined as a plasma $\mathrm{pH}$ less than 7.3, plasma $\mathrm{HCO}_{3}{ }^{-}$less than $18 \mathrm{mmol} / \mathrm{l}$ and ketonuria [8].

Informed consent was obtained from the patients and their parents included in this study.

Statistical analysis. Data are shown as means \pm SD values. The Student's $t$ test for unpaired data, the Fisher's exact test or chi-square test were used, when appropriate. A $p$ value of less than 0.05 was considered significant.

\section{Results}

The prevalence of coeliac disease in our Type I diabetic patients was $8.3 \%$ (32/383). A higher number of girls was found in patients with both diseases in respect of patients with only diabetes $(71.8 \%$ vs $44.7 \%$, $\chi^{2} 8.7, p=0.003$ ). No difference was found between the two groups with regard to both the age $(7.1 \pm 3.3 \mathrm{vs}$ $7.6 \pm 3.8$ years), the prevalence of DKA (53.1\% vs $52.9 \%)$ at diabetes diagnosis and family history of autoimmune disorders ( $18.7 \%$ vs $14.6 \%)$. Out of $32 \mathrm{CD}^{+} \mathrm{T} 1 \mathrm{DM}^{+}$patients six $(18.7 \%)$ had a third autoimmune disease (subclinical autoimmune thyroid disease (three cases), rheumatoid arthritis, psoriasis, autoimmune hepatitis), which was already known or diagnosed at diabetes onset in all cases. In contrast, no one in the $\mathrm{CD}^{-} \mathrm{DM}^{+}$group showed three autoimmune diseases, while 34 out of 351 (9.7\%) of these patients had a second autoimmune disease different from coeliac disease. Only 19 out of $32(59.4 \%) \mathrm{CD}^{+} \mathrm{T} 1 \mathrm{DM}^{+}$ patients were persistently tested negative for EmA and/or IgG AGA after starting GFD. The remaining patients were considered not strictly adherent to a GFD, as they were found to be intermittently positive to the antibody control (at least one positive result out of two yearly evaluations). 
A

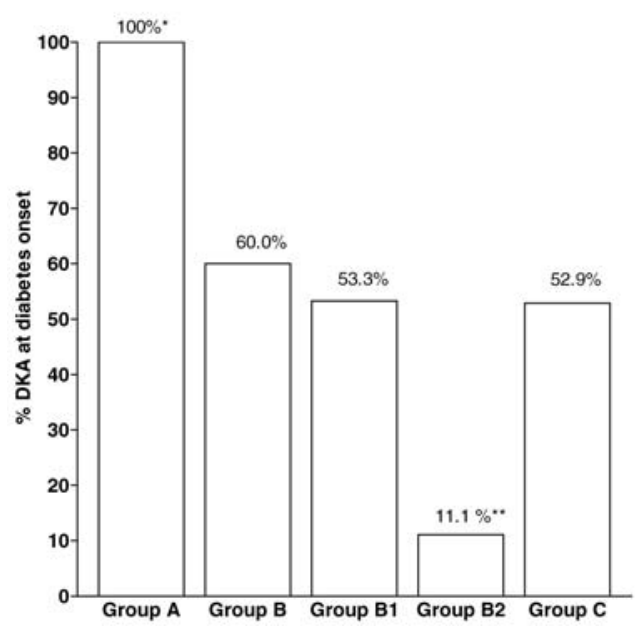

Fig. 1A, B. Prevalence of diabetic ketoacidosis (DKA) at diabetes onset $(\mathbf{A})$ and prevalence of other autoimmune diseases (B) in Type I diabetic patients with and without coeliac disease (CD). $* \chi^{2} 9.4, p=0.009$ (Group A vs Groups B and C); $* * \chi^{2}$ 4.3, $p=0.039$ (Group $\mathrm{B}_{2}$ vs $\mathrm{B}_{1}$ ) and $\chi^{2} 6.2, p=0.013$ (Group $\mathrm{B}_{2}$ vs C); $* * *=0.02$ Fisher's exact test (Group A vs B). Group A: $\mathrm{CD}$ diagnosis before diabetes onset; Group $\mathrm{B}$ : $\mathrm{CD}$ diagnosis after diabetes onset; Group $\mathrm{B}_{1}$ patients with typical and/or atypical $\mathrm{CD}$ symptoms; Group $\mathrm{B}_{2}$ asymptomatic patients. Group C: Type I diabetic patients without CD

Table 1 summarises the comparative analyses among the different groups of patients with both coeliac disease and Type I diabetes. The higher number of girl patients was confirmed in Group A and B patients with respect to Group C $(75.0 \%$ vs $70.8 \%$ vs $44.7 \%$, respectively, $\chi^{2} 8.7, p=0.013$ ), while no substantial difference was found regarding age at diabetes diagnosis. Group A patients showed a higher prevalence of DKA than Groups B and C $(100 \%$ vs $60 \%$ and $52.9 \%$, respectively, $\left.\chi^{2} 9.4, p=0.009\right)$ and increased prevalence of patients with a third autoimmune disease with respect to Group B (50\% vs 8\% respectively, $p=0.02$ ) (Fig.1). Group $\mathrm{B}_{2}$ had less female preponderance than Group $\mathrm{B}_{1}$ and an older age at diabetes onset (Table 1). Moreover, they had a lower prevalence of DKA $(1 / 9,11.1 \%)$ and no other associated autoimmune disease (Fig.1).

The HLA phenotype had the typical pattern (DR3, DQ2) in $85 \%$ cases, which was equally represented in the different $\mathrm{CD}^{+} \mathrm{T} 1 \mathrm{DM}^{+}$groups (data not shown).

\section{Discussion}

Our results confirm the high prevalence $(8.3 \%)$ of coeliac disease in Type I diabetic patients, in accordance with recent reports. In our $\mathrm{CD}^{+} \mathrm{T}_{1 \mathrm{DM}}{ }^{+}$patients, the group with coeliac disease diagnosed before Type I diabetes is well represented, being $25 \%$ of patients, while in other case reports only coeliac disease occasionally precedes the onset of Type I diabetes

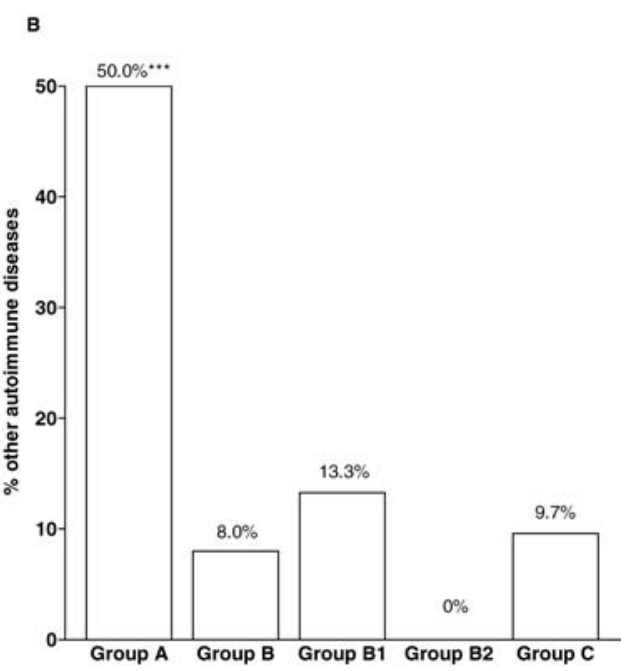

(11.5\%, according to [9]). This difference could be explained by the fact that in our Department there is a centre of Paediatric Gastroenterology, which has in follow-up a very large number of patients with coeliac disease. Even though sex was not a factor in our noncoeliac, diabetic cohort, in accordance with what usually occurs in Type I diabetic patients, a higher female preponderance has been found in our $\mathrm{CD}^{+} \mathrm{T}_{1} \mathrm{DM}^{+}$patients, confirming previous reports on diabetic patients with either coeliac disease [4] or autoimmune thyroid disease $[10,11]$.

Our results indicate that coeliac disease diagnosed before diabetes denotes a subgroup of patients with a more severe clinical presentation of diabetes and higher prevalence of multiple autoimmune diseases. In contrast with this latter finding, it has been reported that the prevalence of autoimmune diseases in patients with coeliac disease is correlated with the time of gluten exposure [12], although conflicting results have been recently reported in adults [13]. Both Type I diabetes and the other autoimmune diseases in Group A patients occurred about 4 years after the start of GFD. Two hypothesis can be made: (i) although these patients were EmA negative at diabetes diagnosis, the adherence to GFD until that time had been not optimal; (ii) GFD was not able to prevent the other autoimmune disorders which had already been triggered. Interestingly, no other autoimmune disorder has been observed in the following 7 years (Table 1 ).

Group $\mathrm{B}_{2}$ subjects (asymptomatic $\mathrm{CD}^{+} \mathrm{T}_{1 \mathrm{DM}}{ }^{+}$patients diagnosed by screening) had the lowest frequency of DKA at diabetes onset and no associated autoimmune disorder. However, a prolonged follow-up is required to observe the eventual occurrence of other autoimmune disorders in this group, because coeliac disease was diagnosed at an older age and only $33 \%$ of these patients were adherent to GFD. In contrast to the other $\mathrm{CD}^{+} \mathrm{T}_{1 \mathrm{DM}}{ }^{+}$groups, a higher number of female patients was not found in Group $\mathrm{B}_{2}$ subjects.

With regard to genetic factors, it has been reported that having the DQA1*05-DQB1*0201 (DQ2) mole- 
cule confers a risk of coeliac disease among Type I diabetic patients [14]. In addition, several studies have investigated additional susceptibility genes to both coeliac disease and Type I diabetes within the HLA region (independent of $H L A-D R$ and $D Q$ genes) and outside the HLA region (CTLA4 gene) $[15,16]$.

Our data underlines that a wide clinical spectrum characterises the association between coeliac disease and Type I diabetes, ranging from mild to severe cases. This finding suggests that detailed molecular studies should be carried out, considering that distinct phenotypes could characterize subjects with both coeliac disease and diabetes mellitus.

\section{References}

1. Fasano A, Catassi C (2001) Current approaches to diagnosis and treatment of coeliac disease: an evolving spectrum. Gastroenterology 120: 636-651

2. De Vitis I, Ghirlanda G, Gasbarrini G (1996) Prevalence of coeliac disease in type I diabetes: a multicentre study. Acta Paediatr Suppl 412: 56-57

3. Cronin CC, Shanahan F (1997) Insulin-dependent diabetes mellitus and coeliac disease. Lancet 349: 1096-1097

4. Acerini CL, Ahmed ML, Ross KM, Sullivan PB, Bird G, Dunger DB (1998) Coeliac disease in children and adolescents with IDDM: clinical characteristics and response to gluten-free diet. Diabet Med 15: 38-44

5. Houlston RS, Tomlinson IP, Ford D et al. (1997) Linkage analysis of candidate regions for coeliac disease genes. Hum Mol Genet 6: 1335-1339

6. Walker-Smith JA, Guandalini S, Schmitz J, Schmerling DH, Visakorpi JK (1990) Revised criteria for diagnosis of coeliac disease. Arch Dis Child 65: 909-911
7. Picarelli A, Maiuri L, Mazzilli MC et al. (1996) Glutensensitive disease with mild enteropathy. Gastroenterology 111: 608-616

8. Ennis ED, Stahl E, Kreisberg RA (1997) Diabetic ketoacidosis. In: Porte D, Sherwin RS, (eds) Diabetes Mellitus. Appleton and Lange, Stamford pp 827-836

9. Pocecco M, Ventura A (1995) Coeliac disease and insulindependent diabetes mellitus: a causal association? Acta Paediatr 84:1432-1433

10. Franzese A, Buono P, Mascolo M, Leo AL, Valerio G (2000) Thyroid autoimmunity starting during the course of type 1 diabetes denotes a subgroup of children with more severe diabetes. Diabetes Care 23: 1201-1202

11. Hansen D, Bennedbaek FN, Hansen LK, Hoier-Madsen M, Jacobsen BB, Hegedus L (1999) Thyroid function morphology and autoimmunity in young patients with insulindependent diabetes mellitus. Eur J Endocrinol 140: 512518

12. Ventura A, Magazzù G, Greco L (1999) Duration of exposure to gluten and risk for autoimmune disorders in patients with coeliac disease. Gastroenterology 117: 297-303

13. Sategna Guidetti C, Solerio E, Scaglione N, Aimo G, Mengozzi G (2001) Duration of gluten exposure in adult coeliac disease does not correlate with the risk for autoimmune disorders. Gut 49: 502-505

14. Šumnì Z, Koloušková S, Cinek O, Kotalová R, Vavrinec J, Šnajderová M (2000) HLA-DQA1*05-DQB1*0201 positivity predisposes to coeliac disease in Czech diabetic children. Acta Paediatr 89: 1426-1430

15. Lie BA, Sollid LM, Ascher H et al. (1999) A gene telomeric of the HLA class I region is involved in predisposition to both type 1 diabetes and coeliac disease. Tissue Antigens 54: $162-168$

16. Naluai AT, Nilsson S, Samuelsson L et al. (2000) The CTLA4/CD28 gene region on chromosome 2q33 confers susceptibility to coeliac disease in a way possibly distinct from that of type 1 diabetes and other chronic inflammatory disorders. Tissue Antigens 56: 350-355 